\title{
Symptomatic Isolated Celiac Artery Dissection following Blunt Trauma
}

\author{
Sang Bong Lee a,c, Hyuk Jae Jung b,c,*, Jae Hun Kim a,c \\ a Department of Trauma Surgery, Pusan National University Hospital, Busan, Korea \\ ${ }^{b}$ Department of Surgery, Pusan National University College of Medicine, Yangsan, Korea \\ ${ }^{c}$ Biomedical Research Institute, Pusan National University Hospital, Pusan, Korea
}

Article history:

Received: October 29, 2018

Revised: February 15, 2019

Accepted: March 4, 2019

\author{
*Corresponding Author: \\ Hyuk Jae Jung \\ Department of Surgery, Pusan \\ National University College of \\ Medicine, Yangsan, Korea \\ E-mail: goodsight@empas.com \\ ORCID \\ https://orcid.org/0000-0003-3407-5855
}

\begin{abstract}
An isolated splanchnic artery injury due to blunt trauma occurs rarely because abdominal vascular injuries are typically associated with injuries to the surrounding abdominal structures, including solid organs or hollow viscus. Of the major abdominal vessels, the celiac artery is the least commonly injured by penetrating or blunt abdominal trauma. Furthermore, a celiac artery dissection due to blunt trauma is rarely reported and there is no clearly defined treatment method, even though endovascular and conservative treatments are accepted widely. On the other hand, endovascular treatment can be challenging if the celiac artery dissection involves its main branch, including the proper hepatic artery, left gastric artery, and splenic artery. This case study presents the treatment experience of a celiac artery dissection involving its main branch following dorsal blunt trauma. Furthermore, conservative treatment is proposed as a treatment option for this rare injury.
\end{abstract}

Keywords: celiac artery, dissection, non penetrating

\section{Introduction}

Isolated celiac artery dissection following blunt trauma is a rare phenomenon. Recently, either endovascular treatment or conservative treatment represented by anticoagulation alone is preferred over surgical intervention in celiac artery dissection. However, endovascular treatment can be challenging if celiac artery dissection involves its main branch including the proper hepatic artery, left gastric artery, and splenic artery. Herein, we present the treatment experience of celiac artery dissection involving its main branch following dorsal blunt trauma, further we propose conservative treatment as a treatment option for a rare injury.

\section{Case Report}

A 40-year-old male was brought to the emergency room presenting with abdominal pain. Three days previously, he was hit by several stacks of tires collapsing onto his back. Abdominal pain began 2 days prior to hospital admission, and gradually worsened, with a squeezing pain around the umbilicus but without nausea and vomiting. His vital signs were stable without fever, and abdominal examination revealed no tenderness, rebound tenderness, or peritoneal signs. He had no medical history, but had presented with hypertension, which was controlled with a calcium channel blocker. All laboratory test results including complete blood count, prothrombin time, creatinine kinase, and D-dimer were 
within the normal range. Abdominal computed tomography (CT) revealed dissection with non-occlusive thrombi in the celiac axis, left gastric artery, and splenic and proper hepatic arteries, but there was no evidence of a visceral organ injury or an infarction (Figure 1).
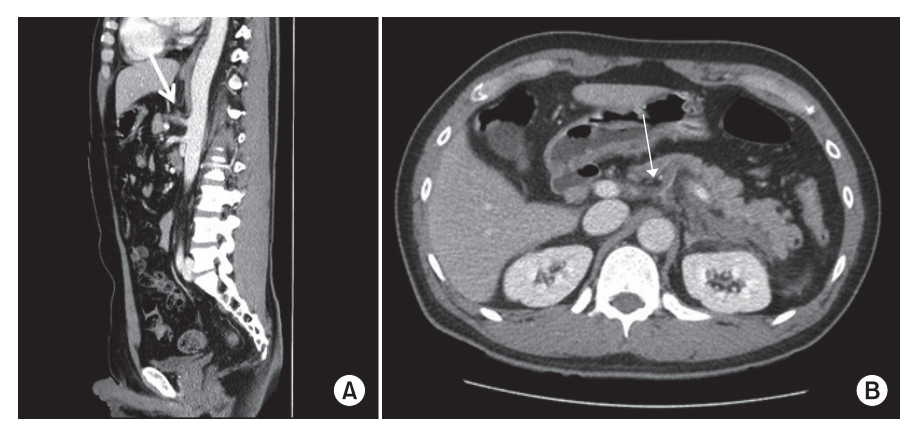

Figure 1. (A) Celiac axis dissection with thrombosed false lumen. (B) Non- occlusive thrombi in the left gastric artery, splenic artery, and proper hepatic artery.

Treatment using subcutaneous low-molecular-weight heparin (enoxaparin, $60 \mathrm{mg} / 12$ hours) was initiated and bowel rest was conducted. The abdominal pain resolved following medical treatment, normal bowel sounds were audible and the patient had flatus. Tolerable diet was initiated on Day 4 and the patient became asymptomatic on Day 6, therefore, the low-molecular-weight heparin was replaced with an oral anticoagulant agent. The patient was discharged from the hospital on day 7 and was followed-up at the outpatient clinic. Three months later, the previously observed dissection and thrombi in the celiac axis, left gastric artery, and splenic and proper hepatic arteries had resolved on follow-up abdominal CT (Figure 2).
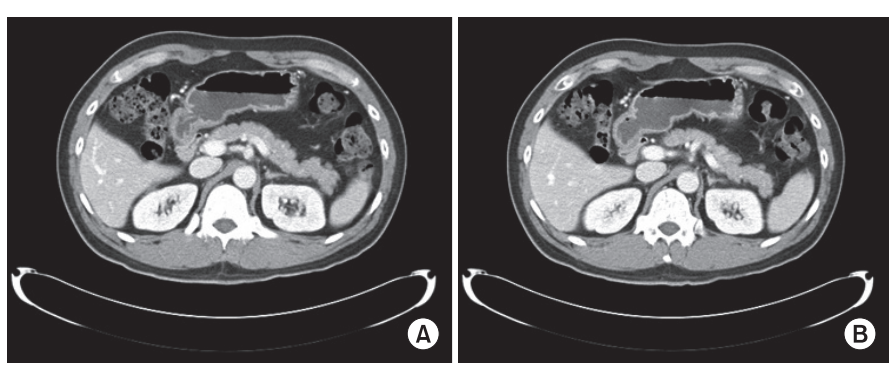

Figure 2. (A) No visible previous non- occlusive thrombi in the celiac axis left gastric artery, splenic artery, and proper hepatic arteries. (B) Improved dissection with thrombosed false lumen.

\section{Discussion}

Celiac artery injury caused by abdominal blunt trauma is rare. Among all the abdominal blood vessels, the celiac artery is the least commonly injured. In a single institution review of 2,357 trauma patients who underwent a laparotomy, the incidence of celiac artery injury was $0.01 \%$ [1]. Thus, it is rare to encounter and have experience in the treatment of isolated celiac artery dissection following blunt trauma. Several reports on isolated celiac artery dissection following abdominal blunt trauma have described the clinical features and various treatment options (Table 1) [2-8]. The most common symptom of celiac artery dissection is abdominal pain. However, the celiac artery has a well-developed collateral arteries, therefore celiac artery dissection may be incidentally discovered in asymptomatic patients. In some reports including present case, abdominal pain may develop several days after an accident. Thus, in a blunt trauma case without arterial dissection on initial CT scan, new-onset abdominal pain should prompt a repeat CT scan to investigate arterial dissection that may have progressed into thrombosis and bowel infarction. Conventional angiography plays a standard role in the diagnosis of visceral vascular injury, however it is not generally used as a diagnostic tool owing to its invasiveness, and because most vascular injuries can be diagnosed by a CT scan. The features of celiac artery dissection on CT include an intimal flap, thrombosed false lumen, aneurysm of the celiac axis or its branch, bowel wall thickening or lack of bowel enhancement [9].

Traditionally, the treatment option for celiac artery dissection was surgery. However, since Yoon et al [10] reported a successful endovascular stent placement in isolated superior mesenteric artery dissection, endovascular stenting rather than surgery has become the primary treatment option for visceral artery dissection.

Generally, the treatment for arterial dissection can be divided for symptomatic and asymptomatic patients. Although celiac artery dissection has been rarely reported, most of the available literature recommends conservative treatment as the primary treatment with either intravenous unfractionated heparin or subcutaneous low-molecular-weight heparin for asymptomatic cases [11]. If there is no change in the extent of arterial dissection on follow-up CT and the patient remains asymptomatic, the patient may be switched to an oral anticoagulant, such as a vitamin $\mathrm{K}$ antagonist or antiplatelet agents. In previous reports, all asymptomatic patients underwent conservative treatment and the results were satisfactory (Table 1) [2-8].

Patients with symptomatic celiac artery dissection have traditionally undergone surgery, but few studies have suggested a standard treatment method because of the small number of cases. In contrast, several treatment methods have been recommended for the more frequent superior mesenteric artery dissection [12,13]. We believe that applying these treatment methods to the celiac artery dissection can help determine the appropriate strategy. Based on previous reports, surgical intervention recommended if the patient complains of abdominal pain and if there are peritoneal 
Table 1 . Recent case reports of isolated celiac artery dissection after blunt trauma.

\begin{tabular}{|c|c|c|c|c|c|}
\hline Source & Age (y)/sex & Mechanism & Symptom & Treatment & Outcome \\
\hline Suchak et al [2] & $41 /$ male & MVC & Epigastric pain on HD 3 & Endovascular stenting & Resolution of abdominal pain \\
\hline Gorra et al [3] & 29/male & Fall down & No symptom & Anticoagulation & $\begin{array}{l}\text { Celiac artery remained occluded. } \\
\text { Patient: asymptomatic }\end{array}$ \\
\hline Kirchhoff et al [4] & 66/male & MVC & Hepatic dysfunction & None & Expired on HD 7 \\
\hline Sarkar et al [5] & 26/male & MVC & No symptom & Anticoagulation & $\begin{array}{l}\text { Complete resolution of } \\
\text { dissection on follow-up image }\end{array}$ \\
\hline Rosenthal et al [6] & 26/male & Fall down & No symptom & Anticoagulation & $\begin{array}{l}\text { Persistent dissection /c stenosis. } \\
\text { Patient: asymptomatic }\end{array}$ \\
\hline Brown et al [7] & $31 /$ male & MVC & No symptom & Anticoagulation & $\begin{array}{l}\text { Celiac artery remained occluded. } \\
\text { Patient: asymptomatic }\end{array}$ \\
\hline \multirow[t]{2}{*}{ Han et al [8] } & 68/male & MVC & Epigastric pain at admission & Anticoagulation & $\begin{array}{l}\text { Persistent dissection } \\
\text { Patient: asymptomatic }\end{array}$ \\
\hline & 49/male & MVC & $\begin{array}{l}\text { Epigastric pain on } 8 \text { days after } \\
\text { accident }\end{array}$ & Anticoagulation & $\begin{array}{l}\text { Improved of dissection } \\
\text { Patient: asymptomatic }\end{array}$ \\
\hline Present case & 40/male & Hit by tiers & $\begin{array}{l}\text { Epigastric pain on } 1 \text { day after } \\
\text { accident }\end{array}$ & Anticoagulation & $\begin{array}{l}\text { Complete resolution of } \\
\text { dissection on follow-up image }\end{array}$ \\
\hline
\end{tabular}

MVC = motor vehicle crash; $\mathrm{HD}=$ hospital days.

signs or evidence of bowel ischemia, however the treatment method for patients with abdominal pain without peritoneal signs or evidence of bowel ischemia is different. Gobble et al [12] suggested that patients with symptoms such as abdominal pain should undergo emergency endovascular stenting to restore blood flow. On the other hand, in patients with abdominal pain without peritoneal signs, Dong et al [13] recommended anticoagulation for 5 days as the primary treatment and selection of the next treatment according to the symptoms. Continued anticoagulation may be considered if the patient remains asymptomatic, but surgical or endovascular intervention should be performed if the patient complains of abdominal pain. Based on the latter's recommendation, anticoagulation therapy was initiated and bowel rest was conducted for the present case. When the patient no longer complained of abdominal pain after 5 days, the treatment was continued with an oral antiplatelet agent. We confirmed the resolution of the dissection on follow-up CT after 3 months, and the patient remained asymptomatic. Han et al [8] also reported the use of anticoagulation as initial treatment in patients without tenderness or peritoneal signs, and the patients' symptom was improved.

Isolated celiac artery dissection due to blunt trauma is rare, and has no clear treatment method. Although, several reports recommended immediate surgical or endovascular intervention for symptomatic patients, our symptomatic case demonstrated that conservative treatment with anticoagulation alone was successful. We believe that if there is no evidence of organ ischemia or peritoneal signs, conservative treatment may be the first treatment option, thereby avoiding unnecessary surgical or endovascular intervention.

\section{Conflicts of Interest}

No potential conflict of interest relevant to this article was reported.

\section{Acknowledgments}

This work was supported by clinical research grant form Pusan National University Hospital in 2018.

\section{References}

[1] Asensio JA, Petrone P, Kimbrell B, Kuncir E. Lessons learned in the management of thirteen celiac axis injuries. South Med J 2005;98(4):462-6.

[2] Suchak AA, Reich D, Ritchie W. Traumatic isolated dissection of the celiac artery. AJR Am J Roentgenol 2007;189(6):W373-4.

[3] Gorra AS, Mittleider D, Clark DE, Gibbs M. Asymptomatic isolated celiac 
artery dissection after a fall. Arch Surg 2009;144(3):279-81.

[4] Kirchhoff C, Stegmaier J, Krotz M, Muetzel Rauch E, Mutschler W, Kanz KG, et al. Celiac dissection after blunt abdominal trauma complicated by acute hepatic failure: case report and review of literature. J Vasc Surg 2007;46(3):576-80.

[5] Sarkar J, Plackett TP, Kellicut DC, Edwards KD. A case report of coeliac artery dissection following a motor vehicle collision. Inj Extra 2012;43(2):15-7.

[6] Rosenthal MG, Cunningham J, Habib J, Kerwin AJ. Isolated celiac artery dissection in blunt abdominal trauma. Am Surg 2015;81(7):E287-90.

[7] Brown CW, Cooper JG, Denison AR, Jansen JO. Coeliac axis dissection secondary to blunt abdominal trauma: a case report and review of the literature. Inj Extra 2014;45(3):19-21.

[8] Han AR, Gwak JH, Choi GK, Park JJ, Yu BC, Lee GJ, et al. Isolated dissection of the celiac artery after blunt trauma: a case report and review of literature. J Trauma Inj 2017;30(4):220-6.
[9] D'Ambrosio N, Friedman B, Siegel D, Katz D, Newatia A, Hines J. Spontaneous isolated dissection of the celiac artery: CT findings in adults. AJR Am J Roentgenol 2007;188(6):W506-11.

[10] Yoon YW, Choi D, Cho SY, Lee DY. Successful treatment of isolated spontaneous superior mesenteric artery dissection with stent placement. Cardiovasc Intervent Radiol 2003;26(5):475-8.

[11] Li S, Cheng L, Tu J, Jiao Y, Wu X, Wang Z, et al. Effectiveness of the conservative therapy for symptomatic isolated celiac artery dissection. Cardiovasc Intervent Radiol 2017;40(7):994-1002.

[12] Gobble RM, Brill ER, Rockman CB, Hecht EM, Lamparello PJ, Jacobowitz GR, et al. Endovascular treatment of spontaneous dissections of the superior mesenteric artery. J Vasc Surg 2009;50(6):1326-32.

[13] Dong Z, Fu W, Chen B, Guo D, Xu X, Wang Y. Treatment of symptomatic isolated dissection of superior mesenteric artery. J Vasc Surg 2013;57(2 Suppl):69-76S. 